Article

\title{
Measurements of Acoustical Parameters in the Ancient Open-Air Theatre of Tyndaris (Sicily, Italy) ${ }^{\dagger}$
}

\author{
Arianna Astolfi ${ }^{1, *\left(\mathbb{C}, \text { Elena Bo }^{1}{ }^{1} \text {, Francesco Aletta }\right.}{ }^{2}{ }^{\mathbb{D}}$ and Louena Shtrepi ${ }^{1}{ }^{1}$ \\ 1 Department of Energy, Politecnico di Torino, 10129 Turin, Italy; elena.bo@polito.it (E.B.); \\ louena.shtrepi@polito.it (L.S.) \\ 2 UCL Institute for Environmental Design and Engineering, The Bartlett, University College London (UCL), \\ London WC1H 0NN, UK; f.aletta@ucl.ac.uk \\ * Correspondence: arianna.astolfi@polito.it; Tel.: +39-011-090-4496 \\ + Part of this work was presented at the ICSV 2016 Conference (Athens, Greece) and the International \\ Conference on Metrology for Archaeology 2015 (Benevento, Italy).
}

Received: 14 July 2020; Accepted: 13 August 2020; Published: 15 August 2020

check for updates

\begin{abstract}
The emerging field of archaeoacoustics is attracting increasing research attention from scholars of different disciplines: the investigation of the acoustic features of ancient open-air theatres is possibly one of its main themes. In this paper, the outcomes of a measurement campaign of acoustical parameters in accordance with ISO 3382-1 in the ancient theatre of Tyndaris (Sicily) are presented and compared with datasets from other sites. Two sound sources were used (firecrackers and dodecahedron) and their differences were analysed. A very good reproducibility has been shown between the two measurement chains, with differences on average of $0.01 \mathrm{~s}$ for reverberation time $T_{20}$, and less than $0.3 \mathrm{~dB}$ for Clarity $C_{50}$ and $C_{80}$ and for sound strength. In general, results show that the reverberation time and strength of sound values are relatively low when compared with other theatres because of the lack of the original architectural element of the scaenae frons. When combining this effect with the obvious condition of an unroofed space, issues emerge in terms of applicability of the protocols recommended in the ISO standard. This raises the question of whether different room acoustics parameters should be used to characterise open-air ancient theatres.
\end{abstract}

Keywords: open-air ancient theatres; acoustical parameters; ISO 3382-1; firecrackers

\section{Introduction}

In recent years, there has been a growing interest in the acoustical characterization of ancient open-air theatres, which led to the development of several research projects (see, e.g., in [1-4]) and a prolific production of scientific literature on the topic (see, e.g., in [5-14]). This reflects a general trend observable in the broader field of archaeoacoustics [15]. There is indeed a renewed attention to the "acoustics of past" [16-18], which is driven by both a pure scholarly interest and a more practical need to adapt historical facilities to contemporary use [9,19-21] and historical relevance, which could help to better understand the design and evolution of other performance spaces [22,23]. However, performing acoustical measurements poses a number of challenges because room acoustics parameters and standards are conceived for enclosed spaces and might not be straightforwardly applicable in outdoor contexts [24,25]. Above all, the ISO 3382-1:2009 standard [26] deals with "performance spaces" but mostly refers to indoor environments (e.g., auditoria, concert halls, etc.). The topic of acoustical characterisation has already been examined in detail for indoor spaces through statistical analysis, in order to investigate the reproducibility of the measures, the accuracy of the parameter calculation [27], the influence of source-receiver position displacement, the measurement chains of different systems [28-30] and the sensitivity to materials characteristics variation [31-33]. The aim of 
this work was to compare two measurement techniques for ancient theatres, using the archaeological site of Tyndaris as case study [34,35]. Particularly, traditional room acoustics measurements have been carried out according to the reference standard ISO 3382-1:2009, with both a dodecahedron source and with firecrackers. The behaviours of the reverberation time, early-to-late energy and sound energy parameters were assessed. The results of the measurements were compared with the findings of other measurement campaigns available in literature and considerations about the applicability of ISO 3382-1 for open-air ancient theatres are presented.

\section{Case Study}

The ancient theatre of Tyndaris was chosen as case study for this measurement campaign that was carried out in September 2015 by the Applied Acoustics Research Group of the Department of Energy of the Politecnico di Torino. The theatre has Greek origins and it was later changed into an arena by the Romans (for this reason Latin terminology has been used throughout this work). Its cavea, made of yellowish local sandstone, has a diameter (d) of $76 \mathrm{~m}$ and only fragments of the monumental scaenae frons still exist (Figure 1). At the time of the measurements the cavea was in part covered by wooden benches and a wooden platform covered the orchestra floor. To the best of the authors' knowledge, no previous room acoustics measurements have been carried out directly in the theatre of Tyndaris.

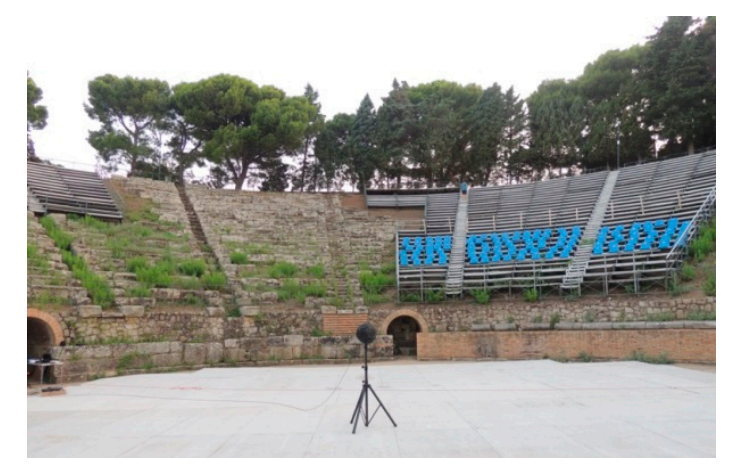

(a)

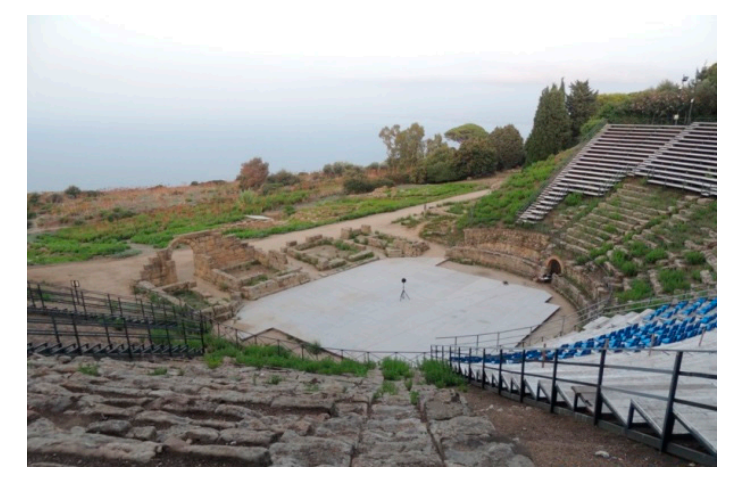

(b)

Figure 1. Present conditions of the ancient theatre of Tyndaris: view from the scaenae (a) and from the cavea (b).

\section{In Situ Measurements}

Acoustical measurements were performed in the theatre in unoccupied conditions, with omnidirectional sound sources and receivers, as per the protocol of the ISO 3382-1:2009 [26]. Further guidance on practical aspects related to the applicability of the ISO standard in the context of ancient open-air theatres was retrieved from other works in literature [1,25]. 
Nine receivers were positioned on three radial axes of the cavea (Figure 2), $1.2 \mathrm{~m}$ off the ground (ear height). An omnidirectional microphone (Schoeps CMC 5-U) was used to record the impulse responses (IRs). For most of the measurement positions, 2-3 repetitions were performed to subsequently evaluate the repeatability of the results. Two source positions were considered: S1 was shifted horizontally by $1 \mathrm{~m}$ from the centre of the orchestra, and S2 was located behind S1, closer to the ancient scaenae frons position. The distance between S1 to S2 was $6.6 \mathrm{~m}$.

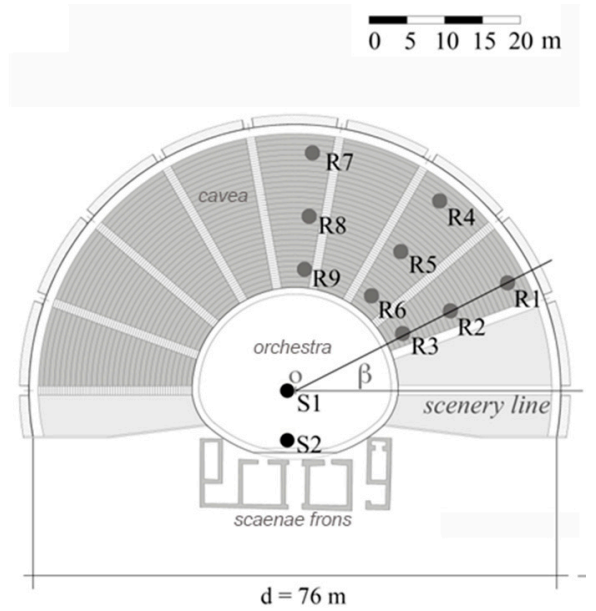

Figure 2. Measurement set-up: S1 and S2 indicate the source positions. R1-R9 indicate the receiver positions. $\mathrm{O}$ is the centre of the orchestra (at a distance of $1 \mathrm{~m}$ from S1, to the left, on the same horizontal axis) and $\beta$ is the angle from the scenery line and the direction that joins the source and the receiver.

Table 1 shows the distances between the sources and the receivers. Two types of sources were used to measure the IRs as it was considered acoustically and metrologically relevant [36]: firecrackers ("Raudo Manna New Ma1b" and "Perfetto C00015 Raudo New") and a dodecahedral source (Bruel \& Kjaer Omnipower sound source 4296). In the former case, the IRs were measured directly by recording the impulse produced by the firecracker blast, while in the latter case, the IRs were obtained after deconvolution of the recorded exponential sine sweep signal, which was $2.73 \mathrm{~s}$ long [26]. The firecracker measurements were only carried out with the source in position S1, apart from one measurement replication that was conducted at receiver R6 with the source in position S2. The IRs from the dodecahedral source were obtained for both source positions S1 and S2. Firecrackers maximize the signal-to-noise ratio (SNR) which is a considerable advantage in outdoor measurements, but they are also more affected by random effects (e.g., atmospheric conditions) [25,36].

Table 1. Source to receiver distances and angle $\beta$ from the scenery line and the direction that joins the source and the receivers, related to the measurement campaign in September 2015 at the theatre of Tyndaris.

\begin{tabular}{ccccc}
\hline Receiver & S1-R $(\mathbf{m})$ & $\mathbf{S 1 -} \boldsymbol{\beta}\left(^{\circ}\right)$ & S2-R $(\mathbf{m})$ & $\mathbf{S 2 -} \boldsymbol{\beta}\left(^{\circ}\right)$ \\
\hline R1 & 32.4 & 25 & 35.7 & 35 \\
R2 & 24.0 & 25 & 27.4 & 37 \\
R3 & 17.0 & 25 & 20.7 & 42 \\
R4 & 32.1 & 52 & 37.5 & 58 \\
R5 & 23.7 & 51 & 29.1 & 59 \\
R6 & 16.7 & 50 & 22.2 & 61 \\
R7 & 31.6 & 83 & 38.1 & 85 \\
R8 & 23.2 & 82 & 29.7 & 84 \\
R9 & 16.2 & 82 & 22.7 & 84 \\
\hline
\end{tabular}


The Background Noise Level (BNL) was measured as an A-weighted equivalent sound level over a period of $10 \mathrm{~min}\left(\mathrm{~L}_{\mathrm{Aeq}}\right.$, 10min $)$, in between measurement sessions and did not overcome $34 \mathrm{~dB}(\mathrm{~A})$. The air temperature and relative humidity were monitored during the whole measurement campaign, using a thermometer/hygrometer, Testo 608-H1 (Croydon South, VIC, Australia). The wind speed was measured by means of an anemometer, Testo 450-V1 (Croydon South, VIC, Australia). Table 2 shows a summary of the environmental conditions during the measurement campaign.

Table 2. Environmental conditions during the two measurement campaigns in September 2015 at the theatre of Tyndaris.

\begin{tabular}{lll}
\hline & 5th September 2015 & 6th September 2015 \\
\hline Type of source & Dodecahedron & Firecrackers \\
Positions of source & 2 & 1 \\
Number of receivers & 9 & 9 \\
Measuring sessions & $21: 00-0: 30$ & $15: 00-17: 30$ \\
Temperature, $\mathrm{t},\left({ }^{\circ} \mathrm{C}\right)$ & $26.2-26.5^{\circ} \mathrm{C}$ & $26.9-28.8^{\circ} \mathrm{C}$ \\
Relative Humidity, $\mathrm{RH},(\%)$ & $77.4-79.4 \%$ & $45.0-69.9 \%$ \\
Wind Speed, $(\mathrm{m} / \mathrm{s})$ & $0.25-0.30 \mathrm{~m} / \mathrm{s}$ & $1.30-1.70 \mathrm{~m} / \mathrm{s}$ \\
\hline
\end{tabular}

The dodecahedral source, powered by an amplifier (Lab.gruppen LAB-300), was connected to a laptop through a soundcard (Tascam US-144). The sound source was positioned at a height of $1.5 \mathrm{~m}$ off the ground, and a custom-made tripod was used to hold the firecrackers in a fixed position. Figure 3 shows the measurement chains of the two source types and a picture of the tripod customized for the firecrackers and the dodecahedron used during the measurements. Two kinds of acquisition software were used for the two measurement chains: Aurora for Audacity 2.4.1 and Dirac version 5.

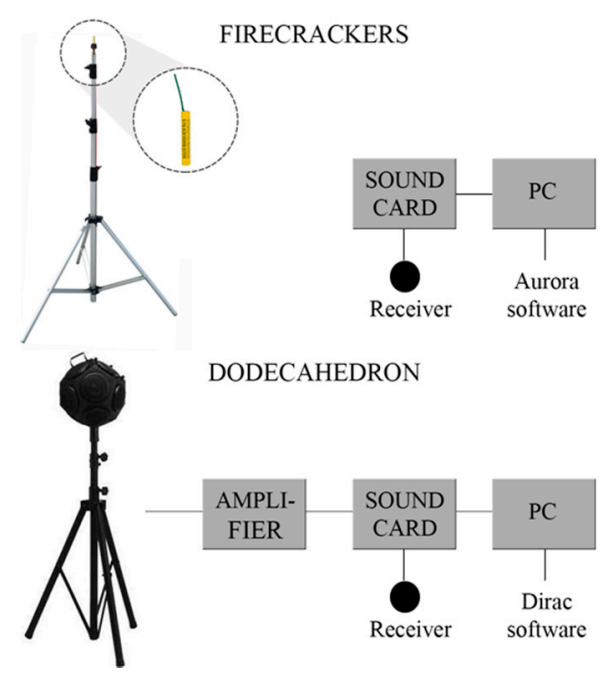

Figure 3. Measurement chains for the two source types-firecrackers (top) and dodecahedron (bottom).

The following parameters, which are commonly used for the acoustical characterization of open-air theatres [7], were computed from the IRs measured at each receiver position; Reverberation Time, $T_{20}(\mathrm{~s})$, which is s a measure of perceived reverberance; Clarity or early-to-late sound index $\mathrm{C}_{80}(\mathrm{~dB})$, which is usually applied for clarity in music [37], and early-to-late sound index $C_{50}(\mathrm{~dB})$, which is usually applied for clarity for speech [38,39]; and Sound Strength, G (dB), which represents a measure of perceived level. A detailed description of the acoustical parameters is reported in the ISO 3382-1 [26] and in [25].

Figure 4 shows a typical IR measured with the firecracker source where, after the direct sound, the main recognisable reflection comes from the orchestra floor, that is, between 2.4 and $2.6 \mathrm{~ms}$ after the 
direct sound for the first row, between 2.8 and $3.0 \mathrm{~ms}$ for the second row and between 3.1 and $3.2 \mathrm{~ms}$ for the third row. Minor scattered reflections from the cavea steps are distinguishable in the latter part.

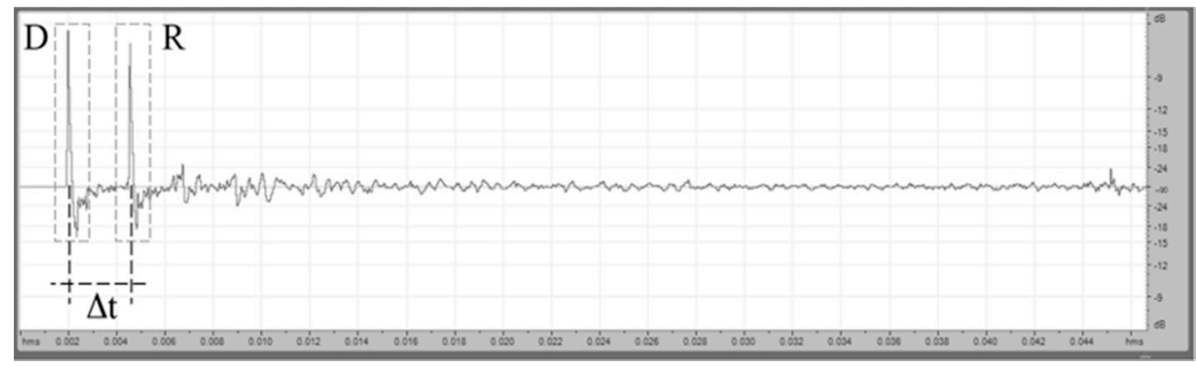

Figure 4. Measured IR in the theatre of Tyndaris for the S1-R6 measurement path and the firecracker source. $\Delta t$ is the time interval between the direct sound $(D)$ and the first reflection $(R)$ from the orchestra floor [34].

The measurements dataset consists of the octave-band values, from $125 \mathrm{~Hz}$ to $8 \mathrm{kHz}$, of the acoustic parameters obtained from the IRs measured with the Dirac software, version 5 , for $T_{20}, C_{50}$ and $C_{80}$, in the case of both the dodecahedral and the firecrackers sources. The $\mathrm{G}$ estimation was performed through Dirac software and Aurora software for Audacity 2.4.1 for the dodecahedral and firecracker sources, respectively. Furthermore, a full compatibility has been checked and verified for the $T_{20}$, $\mathrm{C}_{50}$ and $\mathrm{C}_{80}$ parameters between the two software packages.

Sound Strength, G, is a measure that quantifies the amplification due to the space boundaries relative to a $10 \mathrm{~m}$ free-field reference [26]. A calibration is needed in order to obtain the reference measure. This can consist in the extrapolation of the free-field sound pressure level at $10 \mathrm{~m}$ from the source starting from measurements made at a short distance from the source, in situ, according to the basic spherical spreading law while accounting for source directivity through rotation of the source.

The Dirac software suggests an in situ free-field G calibration consisting of impulse response measurements with the microphone relatively close to the source, at several equally distanced microphone positions around the source [40]. When the measured impulse responses are loaded and a suitable time window, referring to the direct sound and the floor reflection gap, is entered, the system performs the calibration. In this case, three IRs, measured at a distance of $2.5 \mathrm{~m}$ from the source, at different angles all around, in steps of $120^{\circ}$ (in order to average its directivity), were used selecting a time window of $6 \mathrm{~ms}$, which allowed accurate results to be obtained, starting from the $250 \mathrm{~Hz}$ octave band.

Aurora software was used for the G measurement and the analyses of the IRs obtained with the firecrackers signals. According to the procedure suggested on the plugin website [41], the anechoic segment (direct sound) of any IR can be used for calibration, in a similar way to that in [42]. It is recommended to keep a length of the IR of at least $1 \mathrm{~s}$ and to silence the signal just after the end of the direct sound. In this way, the time spread caused by the octave filtering will not result in energy being pushed outside the time window, even at low frequencies, and the correct value of the signal level can be computed. A calibration file was obtained from each analysed IR and was used to calculate the G value for that measurement path, adding the exact source-to-receiver distance. The IR under analysis should be of the same length of the IR used for calibration (at least $1 \mathrm{~s}$ ). Further details are given in [25].

According to the work in [43], in situ G calibration should be avoided because of the uncertainty of individual octave band values, which is much larger than the Just Noticeable Difference (JND) of 1 $\mathrm{dB}$. Actually, repeatability for this measure can bring to differences up to $2 \mathrm{~dB}$ in closed theatres [42]. Nevertheless, the difficulties in performing accurate laboratory calibrations, due to the distant location of the theatre and the likely unsteady outdoor environmental conditions, determined the choice of conducting an in situ calibration. 


\section{Results of the Measurements}

The measurement results are reported in Table 3, expressed as $T_{20}, C_{50}, C_{80}$ and $G$ acoustical parameters, with the dodecahedral source in positions S1 (receivers R1 to R9) and S2 (R1-R8), while Table 4 reports those obtained with firecrackers in positions S1 (R1-R9) and S2 (R6). All the values are the averages of at least two repetitions (apart from some receivers with S2 with dodecahedron) in the same receiver position and of the central $500 \mathrm{~Hz}$ and $1 \mathrm{kHz}$ octave band frequencies, as indicated in ISO 3382-1. Moreover, the spatial average is indicated for each row and as an overall value of the theatre. The Impulse Response-to-Noise Ratio (INR), which is a parameter that establishes the reliability of the acoustical measurements [40], was between $42 \mathrm{~dB}$ and $73 \mathrm{~dB}$ over all the measurements. According to ISO 3382-1, the source level should be at least $35 \mathrm{~dB}$ above the background noise level in the corresponding frequency band for the case of $T_{20}$. With good measurements most practical INR values range from 35 to $60 \mathrm{~dB}$, thus all the measurements considered in this study, for the octave bands from $125 \mathrm{~Hz}$ to $8 \mathrm{kHz}$, comply with this rule.

The results shown in Tables 3 and 4 were obtained from one to five repetitions and give a general overview of the situation, but they are not robust enough to draw conclusions on the uncertainty of the results, due to the high variability of the standard deviations. It is worth highlighting that, in acoustics, parameters are indicators for the perceptual evaluation of an acoustic signal, namely, the average capability of a "conventional" listener to detect sound variations. An important factor that correlates the subjective field to objective measures is the JND, that is, the smallest perceivable change in a given acoustical parameter, which was defined in ISO 3382-1 for central frequencies $(500 \mathrm{~Hz}$ and $1 \mathrm{kHz}$ ). Table 5 shows the JNDs of the acoustical parameters considered in this study [26,44]. Within this framework, a tendency of a uniform pattern of the standard deviations of the spatial means of the parameters can be seen, with values that are closer to the JND values for $T_{20}$ and G, and slightly higher for $\mathrm{C}_{50}$ and $\mathrm{C}_{80}$. In the case of $\mathrm{G}$, as the distance from the source affects the parameter, spatial standard deviations are quite uniform across the different rows, as expected. As general observation, it can be seen that the standard deviations reveal much higher values than the JNDs with the firecracker than with the dodecahedron source. 
Table 3. Mean values of the $T_{20}, C_{80}$ and $G$ acoustical parameters measured with a dodecahedral (D) source at the theatre of Tyndaris with the source in the S1 $1_{D}$ and S2 $\mathrm{D}$ positions. The data refer to the averages of the $500 \mathrm{~Hz}$ and $1 \mathrm{kHz}$ octave bands and to the repetitions for the same receiver position. The rows and overall spatial means are also reported. The standard deviations of the spatial means outside the JND range are shown in bold.

\begin{tabular}{|c|c|c|c|c|c|c|c|c|c|c|c|c|c|}
\hline \multirow{4}{*}{$\begin{array}{l}\text { Acoustical } \\
\text { Parameter }\end{array}$} & \multicolumn{13}{|c|}{$S 1_{D}$} \\
\hline & \multicolumn{13}{|c|}{ Receivers } \\
\hline & \multicolumn{4}{|c|}{ First Row } & \multicolumn{4}{|c|}{ Central Row } & \multicolumn{4}{|c|}{ Last Row } & Overall \\
\hline & R3 & R6 & R9 & Sp. Mean & $\mathbf{R} 2$ & R5 & R8 & Sp. Mean & $\mathbf{R} 1$ & R4 & R7 & Sp. Mean & Sp. Mean \\
\hline N. of repetitions & 2 & 4 & 4 & & 2 & 2 & 5 & & 2 & 2 & 3 & & \\
\hline $\mathrm{T}_{20}(\mathrm{~s})$ & 0.50 & 0.59 & 0.52 & 0.54 & 0.56 & 0.60 & 0.61 & 0.59 & 0.57 & 0.59 & 0.60 & 0.59 & 0.57 \\
\hline St. Dev. $\mathrm{T}_{20}$ & 0.03 & 0.05 & 0.05 & 0.05 & 0.01 & 0.01 & 0.06 & 0.03 & 0.05 & 0.02 & 0.05 & 0.02 & 0.04 \\
\hline $\mathrm{C}_{50}(\mathrm{~dB})$ & 9.7 & 13.3 & 13.4 & 12.1 & 10.8 & 12.8 & 14.3 & 12.3 & 11.0 & 12.2 & 13.1 & 12.1 & 12.3 \\
\hline St. Dev. $C_{50}$ & 1.1 & 2.4 & 2.5 & 2.1 & 1.2 & 1.4 & 3.0 & 1.8 & 0.2 & 0.2 & 2.4 & 1.1 & 1.5 \\
\hline $\mathrm{C}_{80}(\mathrm{~dB})$ & 17.2 & 17.2 & 19.7 & 18.0 & 16.7 & 16.9 & 18.1 & 17.2 & 17.2 & 17.0 & 16.8 & 17.0 & 17.4 \\
\hline St. Dev. $C_{80}$ & 0.8 & 1.2 & 0.7 & 1.5 & 1.2 & 1.4 & 1.5 & 0.8 & 1.2 & 0.8 & 0.6 & 0.2 & 1.0 \\
\hline $\mathrm{G}(\mathrm{dB})$ & 0.4 & -2.2 & -1.0 & -0.9 & -4.9 & -4.1 & -4.2 & -4.3 & -7.8 & -6.8 & -7.1 & -7.2 & -4.2 \\
\hline \multirow[t]{2}{*}{ St. Dev. G } & 0.8 & 1.3 & 0.6 & 1.3 & 0.7 & 1.0 & 0.9 & 0.4 & 0.8 & 0.8 & 0.7 & 0.5 & 2.8 \\
\hline & \multicolumn{13}{|c|}{ S2D } \\
\hline \multirow{3}{*}{$\begin{array}{l}\text { Acoustical } \\
\text { Parameter }\end{array}$} & \multicolumn{13}{|c|}{ Receivers } \\
\hline & \multicolumn{4}{|c|}{ First Row } & \multicolumn{4}{|c|}{ Central Row } & \multicolumn{4}{|c|}{ Last Row } & Overall \\
\hline & R3 & R6 & & Sp. Mean & $\mathbf{R} 2$ & R5 & R8 & Sp. Mean & R1 & R4 & R7 & Sp. Mean & Sp. Mean \\
\hline N. of repetitions & 1 & 1 & & & 1 & 1 & 1 & & 1 & 2 & 3 & & \\
\hline $\mathrm{T}_{20}(\mathrm{~s})$ & 0.53 & 0.51 & & 0.52 & 0.46 & 0.60 & 0.43 & 0.50 & 0.46 & 0.54 & 0.49 & 0.50 & 0.50 \\
\hline St. Dev. $\mathrm{T}_{20}$ & 0.00 & 0.03 & & 0.01 & 0.07 & 0.01 & 0.01 & 0.09 & 0.05 & 0.03 & 0.02 & 0.04 & 0.06 \\
\hline $\mathrm{C}_{50}(\mathrm{~dB})$ & 11.2 & 12.4 & & 11.8 & 11.2 & 13.5 & 16.4 & 13.7 & 10.1 & 13.2 & 15.0 & 12.8 & 12.9 \\
\hline St. Dev. $C_{50}$ & 1.0 & 2.4 & & 0.8 & 0.9 & 1.6 & 1.5 & 2.6 & 2.6 & 1.7 & 1.9 & 2.5 & 2.1 \\
\hline $\mathrm{C}_{80}(\mathrm{~dB})$ & 16.3 & 18.5 & & 17.4 & 18.1 & 17.8 & 19.2 & 18.4 & 17.1 & 17.4 & 18.4 & 17.6 & 17.8 \\
\hline St. Dev. $C_{80}$ & 1.3 & 1.4 & & 1.6 & 1.5 & 1.4 & 1.9 & 0.8 & 2.2 & 1.6 & 1.2 & 0.7 & 0.9 \\
\hline $\mathrm{G}(\mathrm{dB})$ & -2.6 & -3.0 & & -2.8 & -4.9 & -6.2 & -5.5 & -5.6 & -7.4 & -7.6 & -7.6 & -7.5 & -5.6 \\
\hline St. Dev. G & 0.8 & 1.2 & & 0.3 & 1.1 & 1.2 & 1.0 & 0.6 & 1.9 & 1.7 & 1.4 & 0.1 & 2.0 \\
\hline
\end{tabular}


Table 4. Mean values of the $T_{20}, \mathrm{C}_{80}$ and $\mathrm{G}$ acoustical parameters measured with firecrackers $(\mathrm{F})$ at the theatre of Tyndaris with the source in the $\mathrm{S} 1_{\mathrm{F}}$ and $\mathrm{S} 2_{\mathrm{F}}$ positions. The data refer to the averages of the $500 \mathrm{~Hz}$ and $1 \mathrm{kHz}$ octave bands and to the repetitions for the same receiver position. The rows and overall spatial means are also reported. The standard deviations of the spatial means outside the JND range are shown in bold.

\begin{tabular}{|c|c|c|c|c|c|c|c|c|c|c|c|c|c|}
\hline \multirow{3}{*}{$\begin{array}{l}\text { Acoustical } \\
\text { Parameter }\end{array}$} & \multicolumn{13}{|c|}{$\mathbf{S} 1_{F}$} \\
\hline & \multicolumn{13}{|c|}{ Receivers } \\
\hline & \multicolumn{4}{|c|}{ First Row } & \multicolumn{4}{|c|}{ Central Row } & \multicolumn{4}{|c|}{ Last Row } & $\begin{array}{c}\text { Overall } \\
\text { Sp. Mean }\end{array}$ \\
\hline N. of repetitions & 3 & 2 & 2 & & 2 & 2 & 2 & & 2 & 2 & 2 & & \\
\hline $\mathrm{T}_{20}(\mathrm{~s})$ & 0.48 & 0.68 & 0.55 & 0.57 & 0.51 & 0.63 & 0.61 & 0.58 & 0.54 & 0.56 & 0.63 & 0.57 & 0.58 \\
\hline St. Dev. $\mathrm{T}_{20}$ & 0.10 & 0.07 & 0.07 & 0.10 & 0.10 & 0.06 & 0.05 & 0.06 & 0.04 & 0.06 & 0.02 & 0.05 & 0.06 \\
\hline $\mathrm{C}_{80}(\mathrm{~dB})$ & 15.8 & 16.9 & 18.1 & 17.0 & 16.6 & 17.1 & 17.5 & 17.1 & 18.2 & 16.5 & 18.0 & 17.6 & 17.2 \\
\hline St. Dev. $C_{80}$ & 1.5 & 1.3 & 1.3 & 1.2 & 1.0 & 0.4 & 1.7 & 0.5 & 1.1 & 1.0 & 1.2 & 0.9 & 0.8 \\
\hline $\mathrm{G}(\mathrm{dB})$ & 0.0 & -1.7 & -1.2 & -1.0 & -4.6 & -3.9 & -4.2 & -4.2 & -6.8 & -6.7 & -6.3 & -6.6 & -3.9 \\
\hline \multirow[t]{2}{*}{ St. Dev. G } & 0.4 & 0.4 & 0.1 & 0.8 & 0.7 & 0.9 & 0.3 & 0.4 & 0.5 & 0.6 & 1.0 & 0.3 & 2.5 \\
\hline & \multicolumn{13}{|c|}{ S2F } \\
\hline \multirow[t]{2}{*}{ N. of repetitions } & \multicolumn{13}{|c|}{2} \\
\hline & \multicolumn{13}{|c|}{0.52} \\
\hline $\mathrm{T}_{20}(\mathrm{~s})$ & \multicolumn{13}{|c|}{0.52} \\
\hline St. Dev. $T_{20}$ & \multicolumn{13}{|c|}{0.05} \\
\hline $\mathrm{C}_{50}(\mathrm{~dB})$ & \multicolumn{13}{|c|}{11.7} \\
\hline St. Dev. $C_{50}$ & \multicolumn{13}{|c|}{1.4} \\
\hline & \multicolumn{13}{|c|}{17.8} \\
\hline $\mathrm{C}_{80}(\mathrm{~dB})$ & \multicolumn{13}{|c|}{$\begin{array}{c}17.8 \\
1.6\end{array}$} \\
\hline & \multirow{2}{*}{\multicolumn{13}{|c|}{$\begin{array}{l}1.6 \\
0.4\end{array}$}} \\
\hline St. Dev. $C_{80}$ & & & & & & & & & & & & & \\
\hline & \multicolumn{13}{|c|}{-1.9} \\
\hline
\end{tabular}


Table 5. Just Noticeable Difference (JND) of the $T_{20}, \mathrm{C}_{50}, \mathrm{C} 80$ and $\mathrm{G}$ acoustical parameters according to ISO 3382-1 (Annex A) [26] and the work in [44].

\begin{tabular}{cc}
\hline Acoustical Parameter & JND \\
\hline $\mathrm{T}_{20}(\mathrm{~s})$ & $5 \% \approx 0.03$ \\
$\mathrm{C}_{50}(\mathrm{~dB})$ & 1.1 \\
$\mathrm{C}_{80}(\mathrm{~dB})$ & 1 \\
$\mathrm{G}(\mathrm{dB})$ & 1 \\
\hline
\end{tabular}

\subsection{Reverberation Time}

Figure 5 shows the averaged values of $T_{20}$ of all the receivers, considering both source typologies and positions: dodecahedral source in positions S1 and S2, and firecrackers in position S1. The whole theatre mean value, calculated on $0.5-1 \mathrm{kHz}$ octave band frequency range, considering the results from all the sources, is $0.57 \mathrm{~s}$. Standard deviations are approximately $0.04-0.05$ for frequencies from $250 \mathrm{~Hz}$ to $8 \mathrm{kHz}$. Only the firecracker source shows a higher standard deviation at $125 \mathrm{~Hz}$. In general, measurements with both sources in position S1 give similar results for all octave band frequencies, showing higher values with respect to measurements with source S2 in the furthest position.

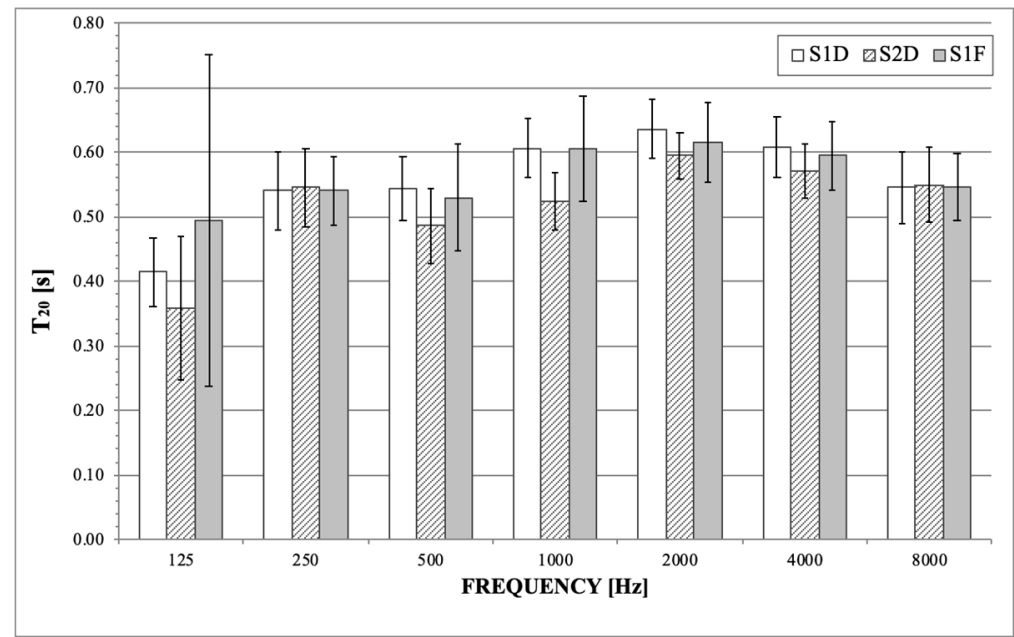

Figure 5. $T_{20}$ measurement results (average values) for all the receivers and sources, expressed as a function of frequency. Standard deviations are reported on the error bars.

\subsection{Early-to-Late Energy Parameters}

Figures 6 and 7 show, respectively, the averaged values of $C_{50}$ and $C_{80}$ of all the receivers as a function of frequency. The whole theatre mean value, calculated on $0.5-1 \mathrm{kHz}$ octave band frequency range, is $12.6 \mathrm{~dB}$ in the case of $C_{50}$, while it is $17.5 \mathrm{~dB}$ in the case of $C_{80}$. Due to the open-air conditions not allowing a proper reverberant tail (that is, late energy), it is not possible to assume that the results are in the typical ISO 3382-1 ranges. The standard deviation of the $C_{50}$ is $\sim 2.5 \mathrm{~dB}$ for all octave band frequencies, while for $C_{80}$ is lower, $\sim 1 \mathrm{~dB}$. Compatible values are shown for all the sources with slightly lower values for $\mathrm{S} 1_{\mathrm{F}}$, i.e., with firecrackers. 


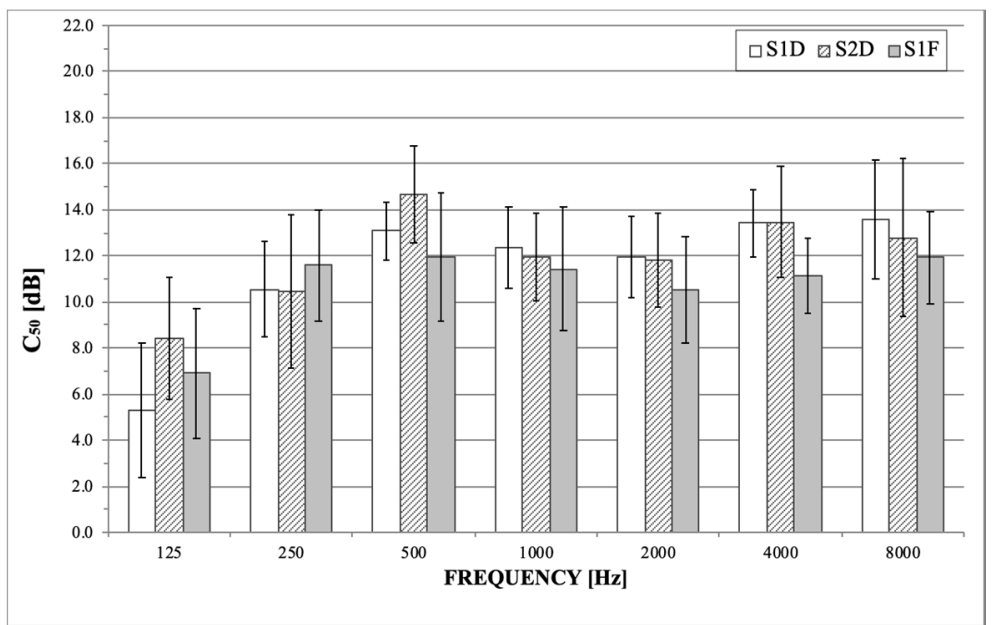

Figure 6. $\mathrm{C}_{50}$ measurement results (average values), for all the receivers and sources, expressed as a function of frequency. Standard deviations are reported on the error bars.

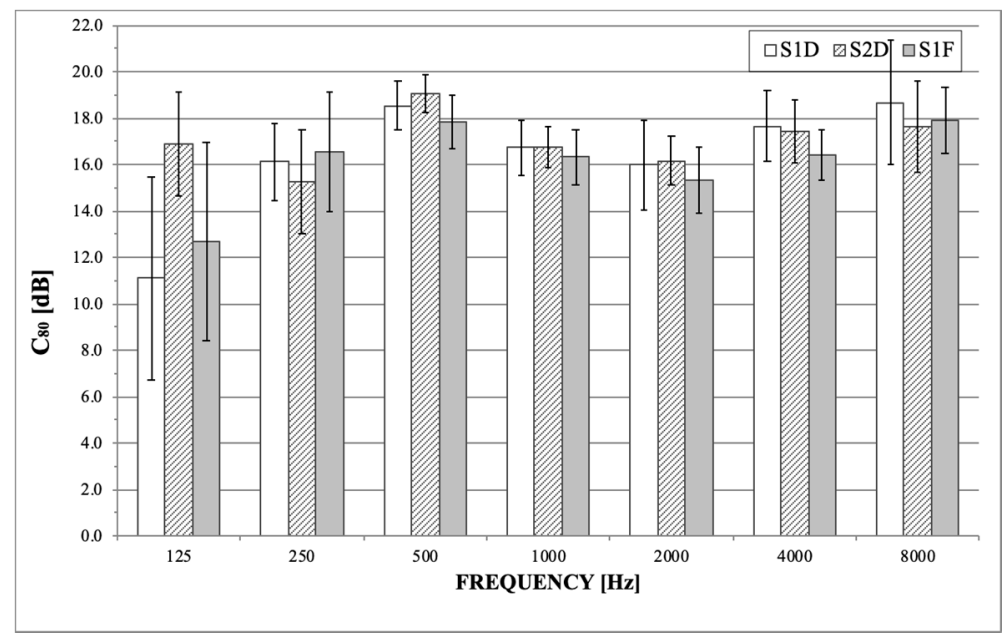

Figure 7. $\mathrm{C}_{80}$ measurement results (average values), for all the receivers and sources, expressed as a function of frequency. Standard deviations are reported on the error bars.

\subsection{Sound Strength}

In Figure 8, the averaged values of Sound Strength $\mathrm{G}$ for $0.5-1 \mathrm{kHz}$ octave band frequency range, $\mathrm{G}_{\mathrm{mid}}$, are shown for each receiver as a function of source-to-receiver distance (d), expressed on a logarithmic scale (the free field linear regression is also reported as a reference). In Table 6, the values of the parameters $A_{i}$ and $B_{i}$ of the equation $G_{\text {mid }}=A_{i}+B_{i} \log _{10}(d)$ are reported for each source position. In all the considered cases, the decay of the $G_{\text {mid }}$ with distance seems to follow quite well the behaviour around a source in free field. The gap between the curves with respect to the free field trend is approximately $3-4 \mathrm{~dB}$ depending on source typology and position. It is possible to conclude that in the theatre the sound strength is low, i.e., in the range from -1 to $-8 \mathrm{~dB}$. Moreover, the source typology seems not to influence the $\mathrm{G}_{\mathrm{mid}}$ results, with differences between $\mathrm{S} 1_{\mathrm{D}}$ and $\mathrm{S} 1_{\mathrm{F}}$ on average values of the first and the second rows of $0.1 \mathrm{~dB}$, and less than $0.6 \mathrm{~dB}$ for the third row, and overall across the theatre of $0.3 \mathrm{~dB}$. This is very promising, as variations of $\mathrm{G}_{\text {mid }}$ results between 1 and $2 \mathrm{~dB}$ are reported in literature for closed theatres related to different calibration procedures and measurement chains $[42,45]$. 


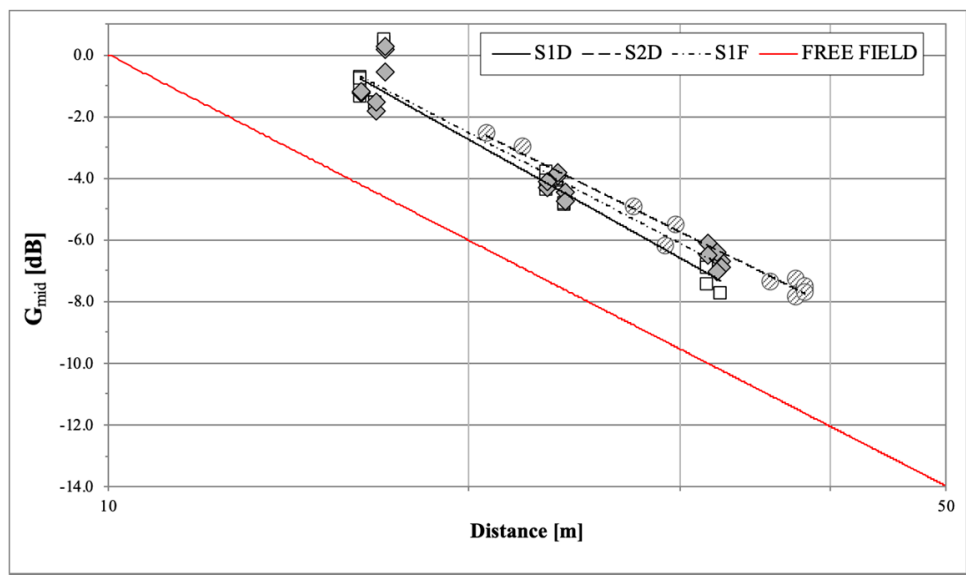

Figure 8. $\mathrm{G}_{\mathrm{mid}}$ averaged $500-1 \mathrm{kHz}$ measurement results for all the receivers and sources, expressed as a function of source-to-receiver distance.

Table 6. Linear regression parameters for the Sound Strength decays in Figure $8\left(G_{\text {mid }}=A_{i}+B_{i} \log _{10} d\right)$, and the related $R^{2}$ coefficient.

\begin{tabular}{cccc}
\hline Source & $\mathbf{A}_{\mathbf{i}}(\mathbf{d B})$ & $\mathbf{B}_{\mathbf{i}}(\mathbf{d B})$ & $\mathbf{R}^{\mathbf{2}}$ \\
\hline Free field & 20 & -20 & 1 \\
S1D & 25.6 & -21.8 & 0.95 \\
S2D & 22.7 & -19.2 & 0.98 \\
S1F & 23.9 & -20.3 & 0.94 \\
\hline
\end{tabular}

\section{Discussion}

\subsection{General Results and Comparison with Other Ancient Theatres}

A first analysis is conducted on the collected IRs structure. The sound field in ancient theatres is generally considered more similar to a free field than a diffuse one. As previously mentioned, there is a limited energetic contribution after the direct sound. This characteristic has consequences both on the extrapolation of the acoustical parameters and their analysis. In fact, all the parameters were calculated from the IRs through their integration in reverse time, strongly affected by the first reflections. Thus, before analysing the whole structure of the IRs, some conclusions are drawn focusing on the Early Decay Curve (EDC), calculated on the squared impulse response.

Figure 9 shows a measured EDC of a typical IR from open-air theatres. The analysis was made with Dirac version 5. As an example, receiver position R6 with dodecahedral source in S1 was chosen as typical EDC. On the x-axis, the arrival time of the direct sound, after the so-called "flight time" starting with the emission of the signal from the source, is indicated. The corresponding IR $\left(S 1_{D}-R_{6}\right)$ is shown in the following Figure 10.

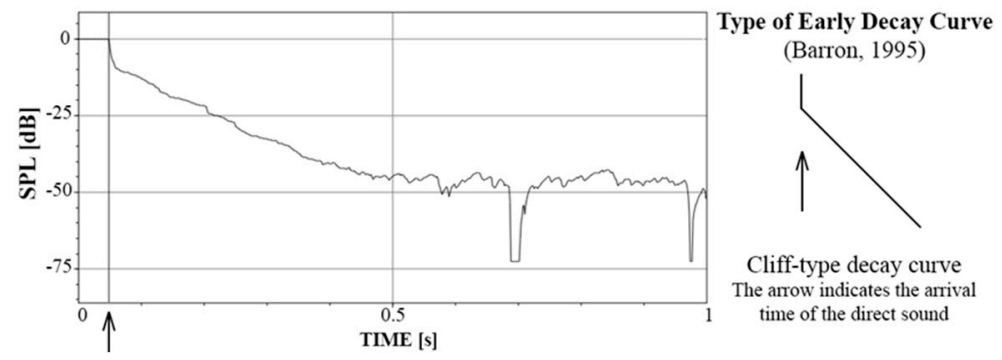

Figure 9. Measured EDC at $1 \mathrm{kHz}$ for the S1-R6 measurement path with dodecahedral source. 
S1D - R6

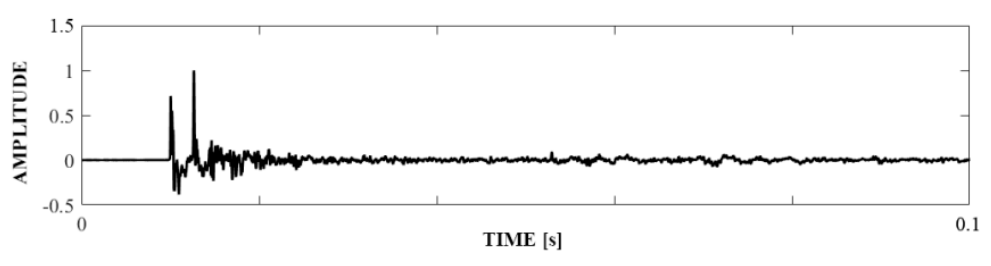

S2D - R6

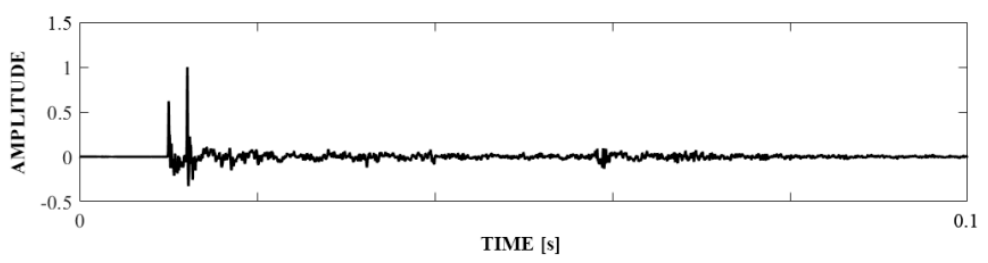

S1F - R6

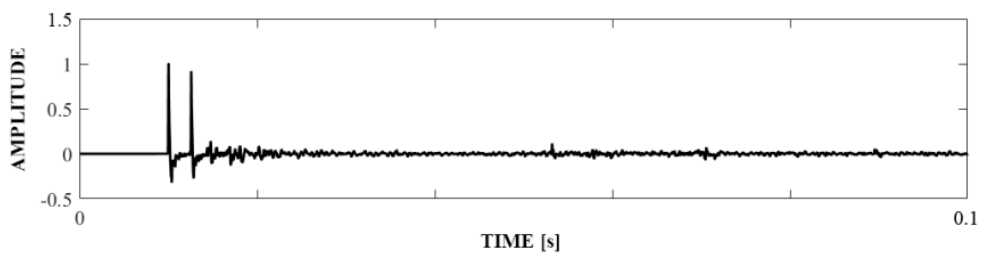

S2F - R6

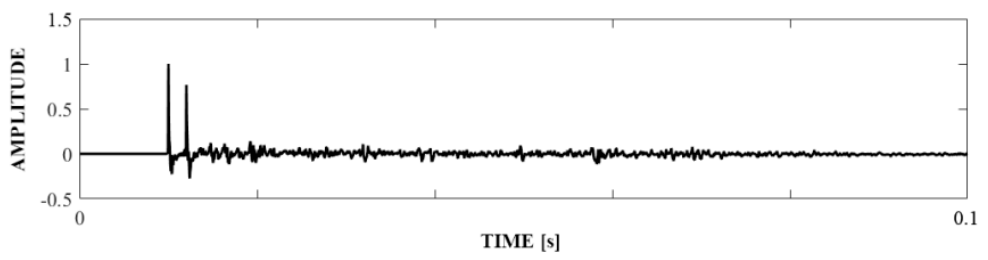

Figure 10. Measured IRs in TYN for R6 position, all the source positions (S1 and S2) and typologies (D and F) considered.

Considering the classification made by Barron [46], this type of EDC is described as "Cliff-type" decay. In this case, either the direct sound or the early reflections are very strong and the direct sound itself could turn out to be not significant with measurements made beyond $10 \mathrm{~m}$ from the source, as in the case of this example. Consequently, Barron reports that this type of EDC is usually leading to Early Decay Time (EDT) shorter than reverberation time such as $T_{20}$ or $T_{30}$, due to the difference between the slopes considered in the decay. EDT is determined from a best fit straight line to the first $10 \mathrm{~dB}$ of sound decays obtained the reverse-time integration of the squared impulse response curve, while for $T_{20}$ the evaluation range of the slope is from $-5 \mathrm{~dB}$ to $-25 \mathrm{~dB}$.

In an open-air theatre, when the sound field substantially differs from a diffuse field, reverberation time is not in principle applicable, but despite this, it is largely used for the acoustic qualification of ancient theatres and for their comparison $[2,3,10,21,47]$. The main contributions to reverberation are few energetic reflections and the scattered sound energy coming from the steps in the cavea. Generally, reverberation time $T_{20}$ or $T_{30}$ show a limited variability in the theatre and for this reason they are used for comparison with other similar theatres. On the contrary, EDT shows a higher variability in the theatre as it is obtained from the very first part of the decay curve and its value is mostly affected by the arrival time and by the energy of the reflections after the direct sound. It is thus not used to obtain an overall qualification of the theatres that allows comparisons between different architectural typologies [7]. In this study, EDT resulted lower than reverberation time and is highly instable, thus in order to avoid the reader making misleading conclusions, it was decided not to show its values. 
Figure 10 shows the fine structure of the typical IRs measured in the theatre with the two source typologies, i.e., the dodecahedron and the firecrackers, obtained for S1-R6 and S2-R6 paths with MATLAB version 2015b.

The IRs clearly show that the main contribution to the direct sound is coming from the first reflection from the orchestra, that is between 2.4 and $2.6 \mathrm{~ms}$ after the direct sound. Then, the first reflection is followed by minor scattered reflections from the cavea steps, distinguishable in the latter part. The absence of a scenic building is responsible for the absence of the third main reflection.

In Figure 10, the IRs obtained with the dodecahedral source show the direct sound with a lower level than the first reflection. This could happen in the case of acoustical focusing, that is, as already mentioned, an effect quite common in ancient theatres [2]. The effect is shown along the R4-R5-R6 and R7-R8-R9 lines for both S1 and S2 only for the dodecahedral source, and it is not observed along the R1-R2-R3 line. It could be due to the lack of omnidirectionality of the dodecahedral source at the highest frequencies $[26,36]$ that determines selected focusing effects due to the loudspeakers position. Considering firecrackers, it does not exhibit directional characteristics or a very good repeatability $[36,48]$. Moreover, IR with the dodecahedral source results to be less sharp than those obtained with firecrackers. This indicates the firecracker source as more suitable than the dodecahedron to obtain defined IRs, at least to investigate the fine structure of the reflection pattern.

Figure 11 reports the frequency trend of the direct sounds extrapolated from the firecracker and dodecahedral sources and compared (measurement path: S1 and R6). The firecrackers direct sound is quite stable and flat until almost $10 \mathrm{kHz}$. However, the firecracker is more subject to problem of repeatability, as shown by the higher level of standard deviations obtained during measurements.

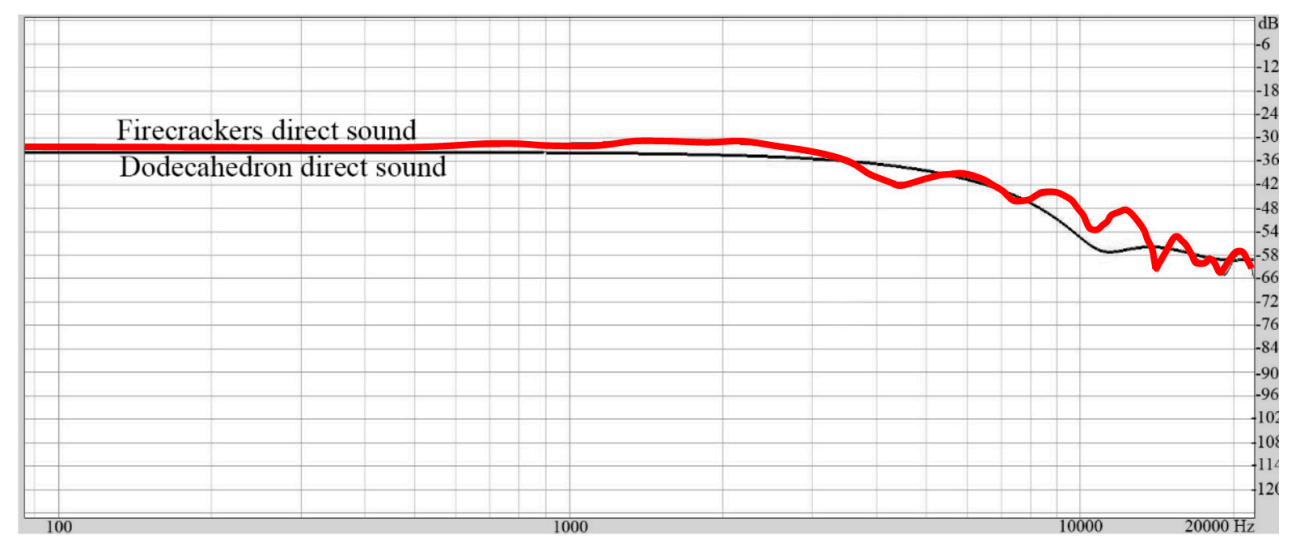

Figure 11. Frequency trend of the direct sound, from firecracker measurements (red line) and dodecahedral source (black line).

A further comparison with other case studies measurements is proposed. The cases considered are the in situ measurements realized on six theatres: Syracusae, Aspendos, Jerash, Taormina, Delphi and Segesta [6,25]. Regarding the in situ measurements, results for Syracusae (Italy, V cent. BCE; Greek-Roman theatre) in this study come from a measurement campaign conducted by the Acoustics Group at Politecnico di Torino in 2015 [25]. Aspendos (Turkey, I cent. CE; Roman theatre) and Jerash (Jordan, I cent. CE; Roman theatre) were the object of measurements during the aforementioned ERATO project. In particular, Aspendos is considered one of the best conserved ancient theatres in the world, as it still preserves architectural elements such as a complete scaenae frons and porticus; Jerash does not have any more a porticus, but it has a partially conserved scaenae frons. Instead, Taormina (Italy, 265-215 BCE, then modified in arena II-III cent. CE; Greek-Roman theatre), Delphi (Greece, II-I cent. BCE, Greek theatre) and Segesta (Italy, IV-I cent. BCE; Greek theatre) were object of another measurement campaign, performed by the University of Ferrara in collaboration with Kobe University [5]. Taormina has a partially conserved scenae frons, while Delphi and Segesta do not have any stage building. This further comparison allows understanding if the performed measurements in Tyndaris are comparable to those realized in previous experiences. 
The results are presented in terms of $\mathrm{RT}_{\mathrm{mid}}$, that is the average value between reverberation time in the octave bands $0.5,1$ and $2 \mathrm{kHz}$, together with the architectural characteristics of the aforementioned theatres as reported in [7], in the following Table 7. It is evident that the complete absence of scaenae frons corresponds to a drastic reduction of the reverberation inside the theatre. Furthermore, it is important to underline that in Tyndaris the theatre cavea is covered by grass and topsoil for some of the area.

Table 7. Main characteristics of the theatre investigated in this work (in bold) compared with other ancient theatres.

\begin{tabular}{lccccccc}
\hline Theatre & $\begin{array}{c}\text { Cavea } \\
\text { Diameter }(\mathbf{m})\end{array}$ & $\begin{array}{c}\text { Seating } \\
\text { Capacity }\end{array}$ & $\begin{array}{c}\text { Cavea } \\
\text { Slope }\end{array}$ & $\begin{array}{c}\text { Scaenae } \\
\text { frons }\end{array}$ & $\begin{array}{c}\text { Scaenae frons } \\
\text { Height }(\mathbf{m})\end{array}$ & $\begin{array}{c}\text { Porticus } \\
\text { RT }_{\text {mid }} \\
\text { (s) }\end{array}$ \\
\hline Tyndaris & $\mathbf{7 6}$ & $\mathbf{7 0 0 0}$ & $\mathbf{2 7 ^ { \circ }}$ & No & - & No & $\mathbf{0 . 5 7}$ \\
Syracusae & 105 & $* 10,000$ & $20-25^{\circ}$ & No & - & No & 0.78 \\
Aspendos & 98 & 15,000 & $33^{\circ}$ & Yes & 26.0 & Yes & 1.68 \\
Jerash & 63 & $* 3000$ & $43^{\circ}$ & Yes (part.) & 8.5 & No & 1.19 \\
Taormina & 109 & $* 5500$ & $39^{\circ}$ & Yes (part.) & 20.0 & No & 1.16 \\
Delphi & 50 & 5000 & $28^{\circ}$ & No & - & No & 0.50 \\
Segesta & 63 & 4000 & $26^{\circ}$ & No & - & No & 0.45 \\
\hline \multicolumn{7}{r}{} \\
\end{tabular}

The $G_{\text {mid }}$ regression lines of the measurements performed in this research are compared to those presented in $[7,25]$ in Figure 12. Considering the in situ measurements, it is evident that to a better state of conservation (i.e., Aspendos and Jerash) corresponds a higher acoustic performance. In particular, for Tyndairs results are in line with those obtained from theatres without preserved scenic building (i.e., Segesta and Delphi), as in all these cases it is possible to count only on the orchestra as acoustic mirror.

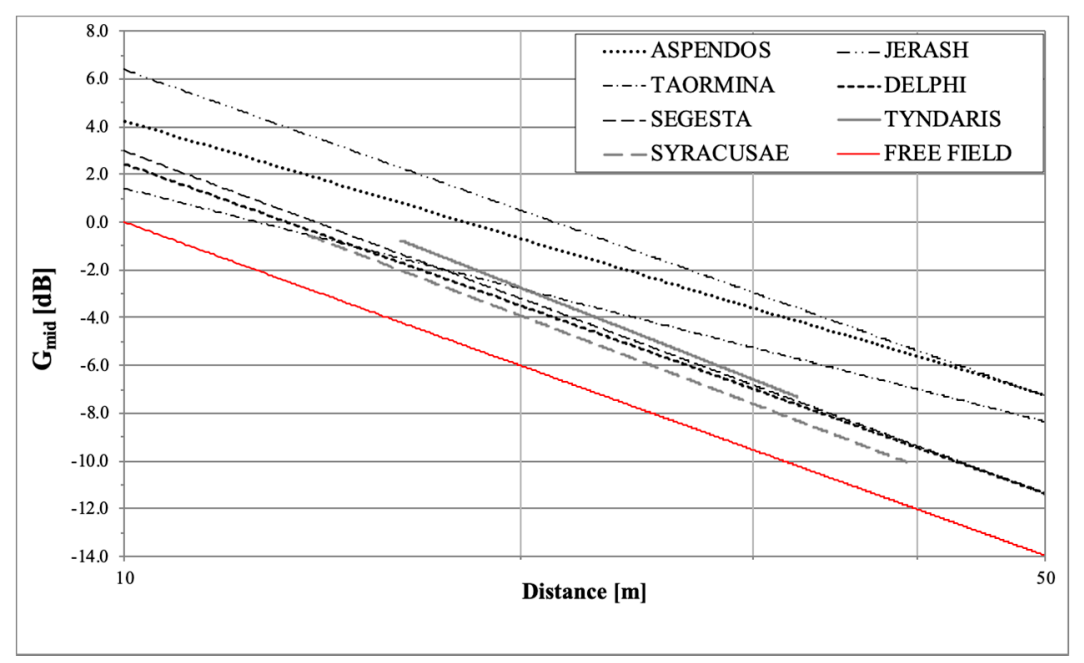

Figure 12. $G_{\text {mid }}$ averaged $0.5-1 \mathrm{kHz}$ measurement results, for all the receivers and sources. Comparison with measurement in real theatres $[7,25]$.

\subsection{Applicability of the ISO 3382-1}

Performing acoustic measurements at archaeological sites is a challenging task and researchers often face a number of practical issues that may require some deviations from standardized protocols [18]. In particular, ISO 3382-1 is meant for roofed performance spaces, thus its straightforward applicability to open-air ancient theatres is problematic at least. Table 8 reports some key recommendations mentioned in different sections of ISO 3382-1 and a brief comment on whether (if applicable and to what extent) those were implemented in the current study. A similar analysis was conducted in [25] and the emerging issues are comparable. 
Table 8. ISO 3382-1 recommendations and their applications in the measurement campaign in Tyndaris.

\begin{tabular}{|c|c|c|c|}
\hline ISO 3382-1 Section & Recommendation & Implemented & Notes \\
\hline \multirow[t]{4}{*}{$\begin{array}{l}\text { 4. Measurement } \\
\text { conditions }\end{array}$} & $\begin{array}{l}\text { Temperature and Relative Humidity: } \\
\text { these quantities should be measured with } \\
\text { an accuracy of } \pm 1^{\circ} \mathrm{C} \text { and } 5 \% \text {, respectively. }\end{array}$ & Yes & $\begin{array}{l}\text { In the case of inter-measurement } \\
\text { temperature change, the } \\
\text { recommended deviation that allows } \\
\text { for accurate measurements of room } \\
\text { acoustic parameters is } 2^{\circ} \mathrm{C}[30] \text {. }\end{array}$ \\
\hline & $\begin{array}{l}\text { Equipment: omnidirectional sources and } \\
\text { receivers. Maximum deviations of } \\
\text { directivity for an omnidirectional source } \\
\text { are indicated. }\end{array}$ & Yes & $\begin{array}{l}\text { The deviation of directivity of the } \\
\text { used sound source respected the } \\
\text { maximum values indicated by the } \\
\text { reference standards. }\end{array}$ \\
\hline & $\begin{array}{l}\text { Number of source positions: minimum } 2 \text {, } \\
\text { located where the natural sound source } \\
\text { would take position. Height of sources: } \\
1.5 \mathrm{~m} \text {. }\end{array}$ & Yes & $\begin{array}{l}\text { Besides taking measurements in two } \\
\text { source positions, also measurements } \\
\text { with two sound source types were } \\
\text { performed. }\end{array}$ \\
\hline & $\begin{array}{l}\text { Number of microphone positions: } \\
\text { Microphone positions should be at } \\
\text { positions representative of positions } \\
\text { where listeners would normally be } \\
\text { located. For reverberation time } \\
\text { measurements, it is important that the } \\
\text { measurement positions sample the entire } \\
\text { space; for the room acoustic parameters, } \\
\text { they should also be selected to provide } \\
\text { information on possible systematic } \\
\text { variations with position in the room. } \\
\text { Height of the receivers: } 1.2 \mathrm{~m} \text {. }\end{array}$ & Yes & \\
\hline $\begin{array}{l}\text { 5. Measurement } \\
\text { procedures }\end{array}$ & $\begin{array}{l}\text { Integrated Impulse Response method: } \\
\text { any source is allowed provided that its } \\
\text { spectrum is broad enough to cover from } \\
125 \mathrm{~Hz} \text { to } 4 \mathrm{kHz} \text {. The peak sound } \\
\text { pressure level has to ensure a decay curve } \\
\text { starting at least } 35 \mathrm{~dB} \text { above the BNL. }\end{array}$ & Yes & $\begin{array}{l}\text { In some receiving positions, the } \\
125 \mathrm{~Hz} \text { frequency band did not } \\
\text { guarantee the required } 35 \mathrm{~dB} \text { over } \\
\text { the } \mathrm{BNL} \text {, with the firecrackers. }\end{array}$ \\
\hline 6. Decay curves & $\begin{array}{l}\text { Regression analysis: a least-squares fit } \\
\text { line shall be computed for the } \\
\text { decay curve. }\end{array}$ & No & $\begin{array}{l}\text { The open-air condition is } \\
\text { characterised by a cliff-decay curve } \\
\text { linked to a few strong reflections, } \\
\text { but this case is not considered by } \\
\text { the standard. }\end{array}$ \\
\hline 7. Uncertainty & $\begin{array}{l}\text { If the impulse response is not exactly } \\
\text { repeatable, results should be the average } \\
\text { of several repeated measurements at the } \\
\text { same position. }\end{array}$ & No & $\begin{array}{l}\text { The standard does not indicate a } \\
\text { suggested number of repetitions, } \\
\text { or a methodology to define it. Since } \\
\text { the priority was to keep stable the } \\
\text { boundary conditions (Temperature, } \\
\text { air Velocity, Relative Humidity), } \\
\text { it was not possible to repeat many } \\
\text { measurements in each position. }\end{array}$ \\
\hline A4. Positions & $\begin{array}{l}\text { A minimum of between } 6 \text { and } 10 \\
\text { microphone positions should be used, } \\
\text { depending on the size of the hall. Above } \\
2000 \text { seats, at least } 10 \text { positions are } \\
\text { suggested. }\end{array}$ & Yes & $\begin{array}{l}\text { Open-air theatres easily reach more } \\
\text { than } 2000 \text { seats, but at farther } \\
\text { positions the measurements may } \\
\text { have easily unreliable results. }\end{array}$ \\
\hline
\end{tabular}

The application of ISO recommendations to the open-air case study is questionable in the evaluation of the correct decay curves, of the measurement uncertainty (using Integrated Impulse Response method) and of the repeatability of the IRs. Thus, it seems fair to assume that the ISO 3382-1 and its parameters, although referred to performance environments, are not completely applicable to open-air spaces. A specific standard for the acoustical measurements in open-air conditions should probably be taken into consideration and added as a further part to the ISO 3382 series. 


\section{Conclusions}

This work presents the results of an acoustical measurements campaign in the ancient open-air theatre of Tyndaris. Measurements based on ISO 3382-1 were conducted in situ in unoccupied conditions using omnidirectional sound sources and receivers. The impulse responses (IRs) were measured directly using a firecracker as the impulse source, and a dodecahedral source, which generated a sine sweep. The acoustical parameters described in the ISO 3382-1 standard, that is, Reverberation Time $\left(T_{20}\right)$, Clarity $\left(C_{50}\right)$ and $\left(C_{80}\right)$ and Sound Strength $(G)$, were obtained from the IRs measured at each receiver position. The following main results are highlighted.

- For Reverberation Time $\left(T_{20}\right)$, the measurements with the firecrackers and the dodecahedron sources returned similar results. When looking at the average value across all source types and positions in the mid-frequencies range, $T_{20}$ was $0.57 \mathrm{~s}$; this value is relatively lower if compared to similar open-air ancient theatres, which is a common trait for those sites where the scaenae frons is no longer in place.

- For the Early-to-Late Energy parameters, the average theatre values in the mid-frequencies ranges are: $\mathrm{C}_{50}=12.6 \mathrm{~dB}$ and $\mathrm{C}_{80}=17.5 \mathrm{~dB}$; yet, such figures should be interpreted with caution as due to operational constraints (open-air conditions) it was not possible to accurately assess the results in alignment with the ISO 3382-1 guidance.

- For the parameter Strength of Sound $G$, the values for the theatre in the mid-frequency range are typically low, going from -1 to $-8 \mathrm{~dB}$, depending on sound source type and position.

A very good reproducibility has been shown between the measurements obtained with the two different measurement chains, with differences on average spatial values for the whole theatre that are equal to $0.01 \mathrm{~s}$ for $T_{20}$, and less than $0.3 \mathrm{~dB}$ for $\mathrm{C}_{50}, \mathrm{C}_{80}$ and $\mathrm{G}$.

Future research should explore additional parameters that could be more suitable for the characterization of the ancient theatre, and unroofed historical spaces more broadly [49]. At other sites, the context should also be taken into account, considering the possible influence of the state of conservation of the architectural elements and materials.

Author Contributions: E.B. and A.A. conceived, designed the data collection campaigns and collected data on site; E.B. performed data analysis together with L.S. and A.A.; A.A., E.B. and F.A. drafted and curated the first version of the manuscript. All the authors revised the paper. All authors have read and agreed to the published version of the manuscript.

Funding: This research was funded through a Ph.D. scholarship awarded to the first author by the Politecnico di Torino (Turin, Italy).

Acknowledgments: The authors are grateful to Fabrizio Bronuzzi, Rocco Costantino and Maurizio Bressan from the Acoustics Laboratory of Politecnico di Torino for their technical contribution to this project. The authors are grateful to Nicola Prodi and Andrea Farnetani from the Univeristy of Ferrara, Angelo Farina from the University of Parma and Monika Rychtarikova from KU Leuven for their suggestions and advice.

Conflicts of Interest: The authors declare no conflict of interest.

\section{References}

1. Rindel, J.H. ERATO; Final Report; Technical University of Denmark: Copenaghen, Denmark, 2006.

2. Rindel, J.H. Roman theatres and revival of their acoustics in the ERATO project. Acta Acust. United Acust. 2013, 99, 21-29. [CrossRef]

3. Hak, C.; Hoekstra, N.; Nicolai, B.; Wenmaekers, W. Project ancient acoustics part 1 of 4: A method for accurate impulse response measurements in large open air theatres. In Proceedings of the 23rd International Congress of Sound Vibrations (ICSV23), Athens, Greece, 10-14 July 2016.

4. Wenmaerkers, R.H.; Nicolai, B.; Hoekstra, N.; Hak, C.C. Project ancient acoustics part 4 of 4: Stage acoustics measured in the odeon of Herodes Atticus and in the theatre of Argos. In Proceedings of the 23rd Internatinational Congress on Sound Vibrations (ICSV23), Athens, Greece, 10-14 July 2016.

5. Sato, S.; Sakai, H.; Prodi, N. Acoustical measurements in ancient Greek and Roman theatres. In Proceedings of the 3rd International Conference of Forum Acusticum, Sevilla, Spain, 16-20 September 2002. 
6. Farnetani, A. Investigation on the Acoustics of Ancient Theatres by Mean of Modern Technologies. Doctoral Dissertation, Università degli Studi di Ferrara, Ferrara, Italy, 2005.

7. Farnetani, A.; Prodi, N.; Pompoli, R. On the acoustics of ancient Greek and Roman theatres. J. Acoust. Soc. Am. 2008, 124, 1557-1567. [CrossRef] [PubMed]

8. Iannace, G.; Trematerra, A.; Masullo, M. The large theatre of Pompeii: Acoustic evolution. Build. Acoust. 2013, 20, 215-227. [CrossRef]

9. Barkas, N. Contemporary sound environment around ancient Greek theatre: Current operation problems. In Proceedings of the Conference SMED “Echo days”, Athens, Greece, 29 September-3 October 2013.

10. Psarras, S.; Hatziantoniou, P.; Kountouras, M.; Tatlas, N.A.; Mourjopolous, J.N.; Skarlatos, D. Measurements and analysis of the Epidaurus theatre acoustics. Acta Acust. United Acust. 2013, 99, 30-39. [CrossRef]

11. Iannace, G.; Trematerra, A. The rediscovery of Benevento Roman theatre acoustics. J. Cult. Herit. 2014, 15, 698-703. [CrossRef]

12. Girón, S.; Álvarez-Corbacho, Á.; Zamarreño, T. Exploring the Acoustics of Ancient Open-Air Theatres. Arch. Acoust. 2020, 45, 181-208.

13. Barkas, N. The Contribution of the Stage Design to the Acoustics of Ancient Greek Theatres. Acoustics 2019, 1, 337-353. [CrossRef]

14. Galindo, M.; Girón, S.; Cebrián, R. Acoustics of performance buildings in Hispania: The Roman theatre and amphitheatre of Segobriga, Spain. Appl. Acoust. 2020, 166, 107373. [CrossRef]

15. Scarre, C.; Lawson, G. Archaeoacoustics; Mc Donald Institute for Archaeological Research: Cambridge, UK, 2006.

16. Till, R. Sound Archaeology: A Study of the Acoustics of Three World Heritage Sites, Spanish Prehistoric Painted Caves, Stonehenge, and Paphos Theatre. Acoustics 2019, 1, 661-692. [CrossRef]

17. Witt, D.E.; Primeau, K.E. Performance Space, Political Theater, and Audibility in Downtown Chaco. Acoustics 2019, 1, 78-91. [CrossRef]

18. Aletta, F.; Kang, J. Historical Acoustics: Relationships between People and Sound over Time. Acoustics 2020, 2, 128-130. [CrossRef]

19. Bo, E.; Astolfi, A.; Pellegrino, A.; Pelegrin-Garcia, D.; Puglisi, G.E.; Shtrepi, L.; Ryctarikova, M. The modern use of ancient theatres related to acoustic and lighting requirements: Stage design guidelines for the Greek theatre of Syracuse. Energy Build. 2014, 95, 106-115. [CrossRef]

20. Bo, E.; Bergoglio, M.; Astolfi, A.; Pellegrino, A. Between the archaeological site and the contemporary stage: An example of acoustic and lighting retrofit with multifunctional purpose in the ancient theatre of Syracuse. Energy Procedia 2015, 78, 913-918. [CrossRef]

21. Berardi, U.; Iannace, G. The acoustic of Roman theatres in Southern Italy and some reflections for their modern uses. Appl. Acoust. 2020, 170, 107530. [CrossRef]

22. D'Orazio, D.; De Cesaris, S.; Morandi, F.; Garai, M. The aesthetics of the Bayreuth Festspielhaus explained by means of acoustic measurements and simulations. J. Cult. Herit. 2018, 34, 151-158. [CrossRef]

23. D'Orazio, D. Italian-Style Opera Houses: A Historical Review. Appl. Sci. 2020, 10, 4613. [CrossRef]

24. Mo, F.; Wang, J. The conventional RT is not applicable for testing the acoustical quality of unroofed theatres. Build. Acoust. 2013, 20, 81-86. [CrossRef]

25. Bo, E.; Shtrepi, L.; Pelegrín García, D.; Barbato, G.; Aletta, F.; Astolfi, A. The Accuracy of Predicted Acoustical Parameters in Ancient Open-Air Theatres: A Case Study in Syracusae. Appl. Sci. 2018, 8, 1393. [CrossRef]

26. International Organization for Standardization. ISO 3382-1:2009 Acoustics-Measurement of Room Acoustic Parameters-Part. 1: Performance Spaces; ISO: Geneva, Switzerland, 2009.

27. Katz, B.F. International Round Robin on Room Acoustical Impulse Response Analysis Software 2004. Acoust. Res. Lett. Online 2004, 5, 158-164. [CrossRef]

28. Pelorson, X.; Vian, J.-P.; Polack, J.-D. On the variability or Room Acoustical Parameters: Reproducibility and Statistical Validity. Appl. Acoust. 1992, 37, 175-198. [CrossRef]

29. Malecki, P.; Zastawnik, M.; Wiciak, J.; Kamisinski, T. The influence of the measurement chain on the impulse response of a reverberation room and its application listening test. Acta Phys. Pol. A 2011, 119, 1027-1030. [CrossRef]

30. Guski, M. Influences of External Error Sources on Measurements of Room Acoustic Parameters. Doctoral Dissertation, RWTH Aachen University, Aachen, Germany, 2015. 
31. Shtrepi, L.; Astolfi, A.; Pelzer, S.; Vitale, R.; Rychtáriková, M. Objective and perceptual assessment of the scattered sound field in a simulated concert hall. J. Acoust. Soc. Am. 2015, 138, 1485-1497. [CrossRef] [PubMed]

32. Shtrepi, L.; Astolfi, A.; D'Antonio, G.; Guski, M. Objective and perceptual evaluation of distance-dependent scattered sound effects in a small variable-acoustics hall. J. Acoust. Soc. Am. 2016, 140, 3651-3662. [CrossRef] [PubMed]

33. Shtrepi, L.; Di Blasio, S.; Asltolfi, A. Listeners Sensitivity to Different Locations of Diffusive Surfaces in Performance Spaces: The Case of a Shoebox Concert Hall. Appl. Sci. 2020, 10, 4370. [CrossRef]

34. Bo, E.; Kostara-Konstantinou, E.; Lepore, F.; Puglisi, G.E.; Shtrepi, L.; Barkas, N.; Astolfi, A. Acoustic characterization of the ancient theatre of Tyndaris: Evaluation and proposals for its reuse. In Proceedings of the 23rd International Congress of Sound Vibrations (ICSV23), Athens, Greece, 10-14 July 2016.

35. Bo, E.; Shtrepi, L.; Pelegrín-García, D.; Barbato, G.; Astolfi, A. Acoustical measurements in ancient theatres: Uncertainty in prediction models. In Proceedings of the 1st International Conference on Metrology for Archaeology, Benevento, Italy, 22-23 October 2015.

36. Papadakis, N.M.; Stavroulakis, G.E. Review of Acoustic Sources Alternatives to a Dodecahedron Speaker. Appl. Sci. 2019, 9, 3705. [CrossRef]

37. Barron, M. Auditorium Acoustics and Architectural Design; Spon Press: London, UK, 1993.

38. Marshall, L.G. Speech intelligibility prediction from calculated C50 values. J. Acoust. Soc. Am. 1995, 98, 2845-2847. [CrossRef]

39. Bradley, J.S. Review of objective room acoustics measures and future needs. Appl. Acoust. 2011, 72, 713-720. [CrossRef]

40. Bruel Kjaer. Dirac Room Acoustics Software; Type 7841, User Manual: Version 5.0; Bruel Kjaer: Nærum, Denmark, 2010.

41. Farina, A. aurora-plugins.com. 2013. Available online: http://pcfarina.eng.unipr.it/Aurora_XP/index.htm (accessed on 7 April 2016).

42. Katz, B.F. In situ calibration of the sound strength parameter G. J. Acoust. Soc. Am. 2015, 138, EL167-EL173. [CrossRef]

43. Wenmaekers, R.H.; Hak, C.C. The sound power as a reference for Sound Strength (G), Speech Level (L), and Support (ST): Uncertainty of laboratory and in-situ calibration. Acta Acust. United Acust. 2015, 101, 892-907. [CrossRef]

44. Bradley, J.S.; Reich, R.; Norcross, S. A just noticeable difference in C50 for speech. Appl. Acoust. 1999, 58, 99-108. [CrossRef]

45. Hak, C.C.; Wenmaekers, R.H.; Hak, J.P.; van Luxemburg, L.C.; Gade, A.C. Sound Strength Calibration Methods. In Proceedings of the ICA 2010 Conference, Sydney, Australia, 23-27 August 2010.

46. Barron, M.B. Interpretation of Early Decay Time in concert auditoria. Acustica 1995, 81, 320-331.

47. Chourmouziadou, K.; Kang, J. Acoustic evolution of ancient Greek and Roman theatres. Appl. Acoust. 2008, 69, 514-529. [CrossRef]

48. Arana, M.; Vela, A.; San Martin, L. Calculating the impulse response in rooms using pseudo-impulsive. Acta Acust. United Acust. 2003, 89, 377-380.

49. Bo, E.; Shtrepi, L.; Aletta, F.; Puglisi, G.E.; Astolfi, A. Geometrical Acoustic Simulation of Open-air Ancient Theatres: Investigation on the Appropriate Objective Parameters for Improved Accuracy. In Proceedings of the 16th IBPSA Conference, Rome, Italy, 2-4 September 2019; pp. 18-25. [CrossRef]

(C) 2020 by the authors. Licensee MDPI, Basel, Switzerland. This article is an open access article distributed under the terms and conditions of the Creative Commons Attribution (CC BY) license (http://creativecommons.org/licenses/by/4.0/). 